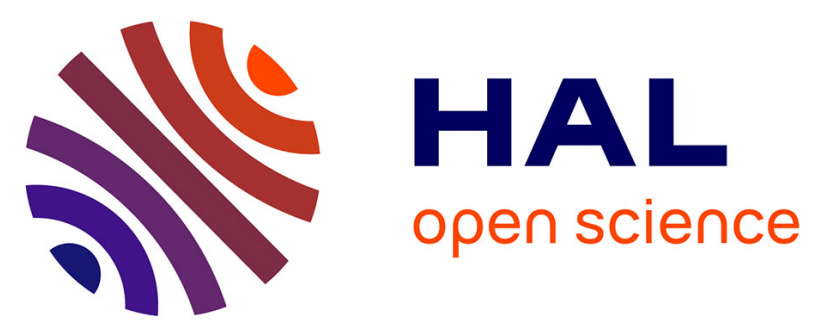

\title{
X-ray absorption spectroscopy investigations on radioactive matter using MARS beamline at SOLEIL synchrotron
}

Isabelle Llorens, Pier lorenzo Solari, Bruno Sitaud, René Bes, Sebastiano Cammelli, Hervé Hermange, Guillaume Othmane, Sami Safi, Philippe Moisy, Sandrine Wahu, et al.

\section{To cite this version:}

Isabelle Llorens, Pier lorenzo Solari, Bruno Sitaud, René Bes, Sebastiano Cammelli, et al.. X-ray absorption spectroscopy investigations on radioactive matter using MARS beamline at SOLEIL synchrotron. Radiochimica Acta, 2014, 102 (11), pp.957 - 972. 10.1515/ract-2013-2241 . hal-03273199v2

\section{HAL Id: hal-03273199 \\ https://hal.science/hal-03273199v2}

Submitted on 29 Jun 2021

HAL is a multi-disciplinary open access archive for the deposit and dissemination of scientific research documents, whether they are published or not. The documents may come from teaching and research institutions in France or abroad, or from public or private research centers.
L'archive ouverte pluridisciplinaire $\mathbf{H A L}$, est destinée au dépôt et à la diffusion de documents scientifiques de niveau recherche, publiés ou non, émanant des établissements d'enseignement et de recherche français ou étrangers, des laboratoires publics ou privés. 
See discussions, stats, and author profiles for this publication at: https://www.researchgate.net/publication/269572684

\section{$\mathrm{X}$-ray absorption spectroscopy investigations on radioactive matter using MARS beamline at SOLEIL synchrotron}

Article in Radiochimica Acta · May 2014

DOI: 10.1515/ract-2013-2241

CITATIONS

21

18 authors, including:

Isabelle Llorens

European Synchrotron Radiation Facility

30 PUBLICATIONS 670 CITATIONS

SEE PROFILE

Sebastiano Cammelli

SOLEIL synchrotron

15 PUBLICATIONS 129 CITATIONS

SEE PROFILE

Some of the authors of this publication are also working on these related projects:

Project FAME and FAME-UHD beamlines View project

Project X-ray emission spectrometer applied to nuclear fuel View project
READS

438

René Bès

University of Helsinki

63 PUBLICATIONS 308 CITATIONS

SEE PROFILE

Hervé Hermange

SOLEIL synchrotron

5 PUBLICATIONS 122 CITATIONS

SEE PROFILE 
Isabelle LLorens, Pier Lorenzo Solari*, Bruno Sitaud, René Bes, Sebastiano Cammelli, Hervé Hermange, Guillaume Othmane, Sami Safi, Philippe Moisy, Sandrine Wahu, Carole Bresson, Michel L. Schlegel, Denis Menut, Jean-Luc Bechade, Philippe Martin, Jean-Louis Hazemann, Olivier Proux, and Christophe Den Auwer

\section{X-ray absorption spectroscopy investigations on radioactive matter using MARS beamline at SOLEIL synchrotron}

\begin{abstract}
The MARS beamline at the SOLEIL synchrotron is dedicated to the characterization of radioactive material samples. One great advantage of the beamline is the possibility to characterize about 380 radionuclides by different X-ray techniques in the same place. This facility is unique in Europe. A wide energy range from around
\end{abstract}

\footnotetext{
*Corresponding author: Pier Lorenzo Solari, Synchrotron SOLEIL,Ligne de lumière MARS, L'Orme des Merisiers, Saint Aubin, BP 48, F-91192 Gif-sur-Yvette Cedex, France, e-mail: pier-lorenzo.solari@synchrotron-soleil.fr Isabelle LLorens, Bruno Sitaud, Sebastiano Cammelli, Hervé Hermange: Synchrotron SOLEIL,Ligne de lumière MARS, L'Orme des Merisiers, Saint Aubin, BP 48, F-91192 Gif-sur-Yvette Cedex, France

René Bes: Synchrotron SOLEIL,Ligne de lumière MARS, L'Orme des Merisiers, Saint Aubin, BP 48, F-91192 Gif-sur-Yvette Cedex, France; and CEA, DEN, DEC, F-13108 Saint Paul Lez Durance Cedex, France Philippe Martin: CEA, DEN, DEC, F-13108 Saint Paul Lez Durance Cedex, France
}

Guillaume Othmane: Institut de Minéralogie et de Physique des Milieux Condensés, UMR 7590 CNRS-Université Pierre et Marie Curie/Paris VI-IRD 4 Place Jussieu, F-75252 Paris Cedex 05, France Sami Safi: Institut de Physique Nucléaire d'Orsay, UMR8608 CNRSUniversité Paris-Sud XI Orsay, 15 Rue Georges Clémenceau, F-91406 Orsay Cedex, France

Philippe Moisy: CEA, Nuclear Energy Division, RadioChemistry and Process Department, F-30207 Bagnols sur Ceze, France

Sandrine Wahu: CEA saclay, DEN/DPC/SECR, F91191 Gif-sur-Yvette Cedex, France

Carole Bresson, Michel L. Schlegel: CEA saclay, DEN/DPC/SEARS, F91191 Gif-sur-Yvette Cedex, France

Denis Menut, Jean-Luc Bechade: CEA, DEN, Service de Recherches Métallurgiques Appliquées, F-91191 Gif-sur-Yvette Cedex, France Jean-Louis Hazemann: Institut Néel, UPR 2940 CNRS, F-38042 Grenoble Cedex 9, France

Olivier Proux: Observatoire des Sciences de l'Univers de Grenoble, UMS 832 CNRS Université Joseph Fourier, F-38041 Grenoble Cedex 9, France

Christophe Den Auwer: Institut de Chimie de Nice, UMR7272 CNRSUniversité de Nice Sophia Antipolis, Campus Valrose, 28 Avenue Valrose, F-06108 Nice Cedex 2, France
$3.5 \mathrm{keV}$ to $36 \mathrm{keV}$ K-edges from $\mathrm{K}$ to $\mathrm{Cs}$, and L3 edges from $\mathrm{Cd}$ to $\mathrm{Am}$ and beyond can be used. The MARS beamline is optimized for X-ray absorption spectroscopy techniques (XANES/EXAFS), powder diffraction (XRD) but x-ray fluorescence (XRF) analysis, High Energy Resolution Fluorescence Detected -XAS (HERFD-XAS), X-ray Emission (XES) and $\mu$-XAS/XRD are also possible. A description of the beamline as well as its performances are given in a first part. Then some scientific examples of XAS studies from users are presented which cover a wide variety of topics in radiochemistry and nuclear materials.

Keywords: Synchrotron, X-rays, XAS, HERFD-XAS, Uranium, Neptunium, Zirconium, Molybdenum, Thorium.

DOI 10.1515/ract-2013-2241

Received December 13, 2013; accepted April 11, 2014

\section{Introduction}

X-ray Absorption Spectroscopy (XAS) is a powerful tool to obtain information at the molecular-level regarding elements speciation studies. Speciation describes the nature of the element but also its oxidation state, its coordination geometry (also given by X-ray Absorption Near Edge Structure - XANES) and the local environment i.e. the type of neighbouring atoms, coordination number and bond distances (given by Extended X-ray Absorption Fine Structure - EXAFS) [1]. The main advantages of the XAS technique are its subatomic resolution (angstrom), the ability to analyze almost any type of samples whatever its form (solid or liquid), the possibility to analyze such samples in-situ with minor or no sample preparation, and a good sensitivity down to $\mathrm{mM}$ or tens of ppm concentrations. The technique is thus quite a powerful tool to study radioactive materials, since in addition the large penetration depth of Xrays allows measurements on confined samples. Because 
it is a second-order phenomenon and requires bright Xray beam over a continuum range of X-ray energies, XAS has been developed almost exclusively on synchrotron radiation facilities. Today, more than 86 beamlines over the world are now dedicated to XAS. However, only seven beamlines using XAS or related techniques over the world are partially or totally dedicated to radionuclides studies: BL27B at Photon Factory (Tsukuba, Japan) [2], BL23SU at Spring8 (Harima, Japan) [3], BL 11-2 at the SSRL (Menlo Park,California, USA) [4], ROBL (BM20) at ESRF (Grenoble, France) [5], INE at ANKA (Karlsruhe, Germany) [6], MicroXAS at SLS (Villigen, Switzerland) [7] and MARS at SOLEIL (Saint-Aubin, France). BL27B at Photon Factory (Tsukuba, Japan) is the first beamline in operation for radionuclide studies since 1995 and MARS beamline is currently the last one in operation since 2010.

MARS beamline is installed on a $1.71 \mathrm{~T}$ bending magnet of the SOLEIL synchrotron storage ring operating at $2.75 \mathrm{GeV}$. It is a unique facility where about 380 radionuclides have been authorized for characterizations by different X-ray techniques. Indeed, in addition to XAS and related techniques, X-ray diffraction (XRD) and X-ray fluorescence (XRF) measurements can also be performed [8]. The energies of the $\mathrm{X}$-rays produced on the beamline are in the "hard" range between 3.5 and $36 \mathrm{keV}$, thus covering $\mathrm{K}$-edges from $\mathrm{K}$ to $\mathrm{Cs}$, and $L_{3}$ edges from $\mathrm{Cd}$ to $\mathrm{Am}$ and beyond.

This paper focuses on the possibilities available to users for characterization by XAS since 2011. The beamline design (Sect. 2.1) and its technical specifications (Sect. 2.2) as well as the standard equipment of XAS experimental station (Sect. 2.3) are described. Results obtained by users that are covering a wide variety of topics in radiochemistry and nuclear materials (Sect. 3) are briefly presented.

\section{Beamline}

Authorized samples on MARS beamline can be liquid or solid. All types of emitters ( $\alpha, \beta, \gamma$ and $n$ emitters) can be received on the beamline up to a maximal activity of $2 \mathrm{GBq}$ for $\gamma$ emitters and $18.5 \mathrm{GBq}$ for $\alpha$ emitters with a dose rate limited to a maximum of $2 \mathrm{mSv} / \mathrm{h}$ in the experimental and storage room. Radioactive samples characterized on the beamline have to be continuously surrounded by at least one static barrier confinement depending on their forms. Thus, non-contaminating solid samples will be confined by a single barrier, contaminating solid samples by a double barrier, and liquid samples by two confinement barriers. For highly irradiating samples it is foreseen to have additional semi-removable shieldings around samples and also around endstations in order to respect the dose rate limitations.

\subsection{Infrastructure}

The infrastructure of the beamline (Figure 1) has been designed to guarantee safe activities with radionuclides. It consists of three main functional areas: the optic hutch, the control room and a central area comprising a room for safety controls of sample packaging and storage as well as the experimental hutch. The different hutches were designed by SOLEIL and their construction was realized by

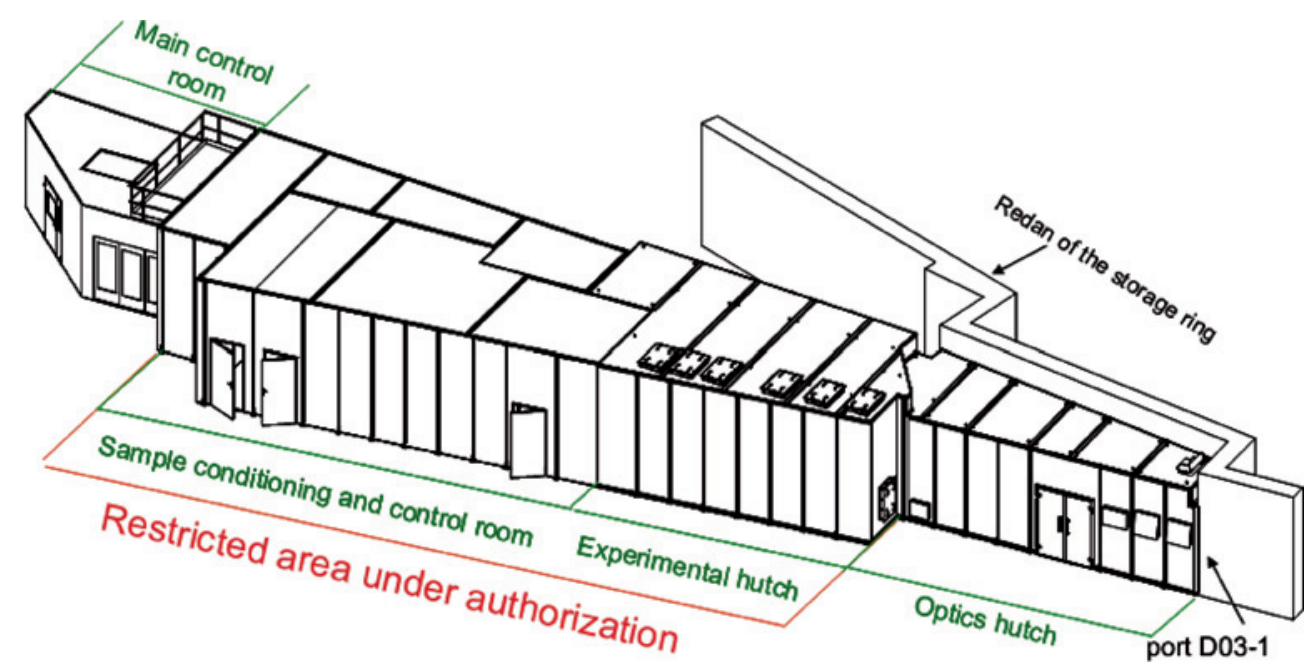

Fig. 1: General layout of the MARS beamline from the optics hutch (right side) to the control room (left side). The central part is the restricted area for radioactive sample preparation and experiments. Copyright 2009 IOP Science. 
NTC Company (France). Special infrastructural solutions have been implemented, in particular in the central area, where radionuclides are hosted. For example, this area is set under depressurized atmosphere in order to ensure a dynamical confinement. This is achieved thanks to the dedicated ventilation system with special absolute filters, the implementation of special walls with air-tight internal layers and air-tight cables feed-throughs. The ventilation system was designed and constructed by COFATHEC Company (France). Furthermore, the internal infrastructural components are built with fire-resistant materials for a period of $2 \mathrm{~h}$ and their external surfaces can be easily cleaned in case of contamination (see ref. [9] for more details).

\subsection{Optics}

\subsubsection{Primary optics}

The optical design of the beamline has been carried out in order to have the maximum X-ray beam flux on the sample and ensure an optimal spatial stability inside the full energy range. A complete description of the beamline optics has been already detailed previously $[8,10]$. The optics of the beamline is designed to operate in two different main configurations with monochromatic or polychromatic ("white/pink") X-ray beam, respectively. This latter option was included at the beamline conception to allow dispersive XAS measurements (now abandoned). In addition to this standard "macrobeam"mode, the beamline can also operate in a "microbeam" mode by inserting secondary focusing optics (see details in Sect. 2.2.2 in the following).

All the main optical elements are located in a first shielded hutch at the beginning of the beamline just after the front-end.

In the monochromatic mode, the main elements that are used are a double crystal monochromator surrounded by two mirrors. All elements are water cooled with chiller systems.

The mirrors, manufactured by IRELEC (France) and SESO (France), consist of two strips: Si uncoated strip for energies below $14 \mathrm{keV}$ and $60 \mathrm{~nm}$ Pt-coated strip for high energies.

The functions of the $1^{\text {st }}$ mirror are the following:

- Collimation of the incident beam in order to optimize the energy resolution of the monochromator,

- Rejection of the high energy harmonics intensity by varying the angle between 2 and $4 \mathrm{mrad}$,
- Reduction of the heat loaded on the $1^{\text {st }}$ crystal of the monochromator.

The two-crystal monochromator, manufactured by FBM Oxford Ltd. (UK), is located just after the $1^{\text {st }}$ collimating mirror at a distance of $14.4 \mathrm{~m}$ from the source. Its main purpose is to select the proper energy according to the Bragg law. Two sets of crystals, $\mathrm{Si}(111)$ and $\mathrm{Si}(220)$, are available for covering the $3.5-36 \mathrm{keV}$ energy range. The $1^{\text {st }}$ crystals are water cooled to limit the thermal bump and the $2^{\text {nd }}$ crystals are dynamically curved (from $1.6 \mathrm{~m}$ to $\infty$ ) on the same bender during energy scans in order to keep the beam focused on the sample in the horizontal plane. The horizontal size of the spot is around $300 \mu \mathrm{m}$ (Full Width at Half Maximum).

The $2^{\text {nd }}$ mirror is located after the monochromator. Its purposes are to eliminate the remaining harmonics and mainly to focus the beam in the vertical plane on the sample. The vertical size of the beam on the sample is around $300 \mu \mathrm{m}$ (FWHM).

\subsubsection{Beamline performances}

Flux. In the standard conditions of work, with a primary slit opening of $20 \times 2 \mathrm{~mm}^{2}(\mathrm{H} \times \mathrm{V})$ corresponding to an angular aperture of $1.75 \times 0.18 \mathrm{mrad}^{2}$ and a machine current of $430 \mathrm{~mA}$, the photon fluxes measured at the sample position of the XAS end-station ( $26 \mathrm{~m}$ from the source) using both the $\mathrm{Si}(111)$ and $\mathrm{Si}(220)$ crystals of the monochromator are shown in Figure 2a.

Stability of the beamline. Over a long period $(\Delta \mathrm{T}=$ $10 \mathrm{~h}$ ) and without any energy displacement, the optimization of the beamline is achieved with a noise of $0.2 \%$ root mean square on the $I_{0} / I_{\mathrm{SR}}$ ratio for a counting time equal to $1 \mathrm{~s}$ per point at $32.513 \mathrm{keV}\left(\theta_{\mathrm{Bragg}}=5.4467^{\circ}\right)$ with a storage ring operating in 8-bunches in top-up mode $(\sim 88.31 \mathrm{~mA})$ (Figure $2 \mathrm{~b})$. This value is significantly good since it is obtained for a low $\theta_{\text {Bragg }}$ value, for which any vibration can be noticeable, and in a low-current operating mode. Therefore the noise is expected to be even smaller with a higher storage ring current, and for lower X-ray energy (i.e. higher Bragg angle). The intensity of the X-ray monochromatic beam $I_{0}$, measured after the monochromator presents discontinuities due to the periodic top-up refill of the SOLEIL storage ring $\left(I_{\mathrm{SR}}\right)$ but the ratio $I_{0} / I_{\mathrm{SR}}$ is constant. To estimate the quality of the beamline stability, we performed several energy scans on $1 \mathrm{keV}$ for an acquisition time of approximately $70 \mathrm{~min}$ per scan (Figure 2c). They are performed between 17 and $18 \mathrm{keV}$ using the $\mathrm{Si}(220)$ monochromator which represents the most common configuration of the beamline. For a period of 
Table 1: Comparison between the experimental $\left(\Delta E_{\text {measured }}\right)$ and theoretical $\left(\Delta E_{\mathrm{th}}\right)$ FWHM of the XANES pre-edge peak for metallic references.

\begin{tabular}{lrrrrrr}
\hline & $\begin{array}{r}\text { K-edge } \\
\text { energy } \\
(\mathrm{keV})\end{array}$ & $\begin{array}{r}\text { Mono- } \\
\text { chro- } \\
\text { mator }\end{array}$ & $\begin{array}{r}\boldsymbol{\theta}_{\text {Bragg }} \\
\left({ }^{\circ}\right)\end{array}$ & $\begin{array}{r}\boldsymbol{\delta} \boldsymbol{\varepsilon} \\
(\mathrm{eV})\end{array}$ & $\begin{array}{r}\Delta E_{\text {th }} \\
(\mathrm{eV})\end{array}$ & $\begin{array}{r}\Delta E_{\text {measured }} \\
(\mathrm{eV})\end{array}$ \\
\hline $\mathrm{Cr}$ & 5.989 & $\mathrm{Si}(111)$ & 19.3 & 0.973 & 1.39 & 1.69 \\
$\mathrm{Fe}$ & 7.112 & $\mathrm{Si}(111)$ & 16.2 & 0.819 & 1.69 & 1.85 \\
$\mathrm{Y}$ & 17.038 & $\mathrm{Si}(220)$ & 11.9 & 0.874 & 3.63 & 3.76 \\
$\mathrm{Nb}$ & 18.986 & $\mathrm{Si}(220)$ & 9.8 & 0.973 & 4.25 & 4.50 \\
\hline
\end{tabular}

$35 \mathrm{~h}$ ( $\sim 30$ scans), the standard deviation on the incident intensity is lower than $0.4 \%$. Scans were collected with a storage ring functioning in 8-bunches mode which implies more frequent refills than in multi-bunches mode and therefore a greater standard deviation.

Energy resolution. The energy resolution of the beamline can be evaluated by comparing the experimental FWHM of the XANES pre-edge features for metallic references ( $\triangle \mathrm{E}_{\text {measured }}$ ) with the equivalent theoretical value $\left(\Delta \mathrm{E}_{\mathrm{th}}\right)$, as shown in Table 1. XANES K-edge spectra (not shown) have been collected in the transmission mode for pure metallic references of $\mathrm{Cr}$ and $\mathrm{Fe}$ using $\mathrm{Si}(111)$ monochromator; $\mathrm{Y}$ and $\mathrm{Nb}$ using $\operatorname{Si}(220) . \Delta \mathrm{E}_{\text {measured }}$ was estimated by fitting the pre-edge with a combination of an Arctangent and Gaussian contributions using Peak Fit implemented in Athena software [11]. The centroids, amplitudes, and widths of the various line shapes are either fixed or varied during iteration steps. Fits lead to Rfactor values between $0.0024-0.0059$ and $\chi^{2}$ values of $0.023-0.074 . \Delta \mathrm{E}_{\text {th }}$ was calculated following the expression $\sqrt{\Gamma_{i}^{2}+\Gamma_{f}^{2}+\delta \varepsilon^{2}}$ with $\Gamma_{\mathrm{i}}$ and $\Gamma_{\mathrm{f}}$ : initial and final states core-hole lifetime broadenings $(\mathrm{eV})$ [12], $\delta \varepsilon$ : crystals intrinsic resolution of $\mathrm{Si}(111)$ or $\mathrm{Si}(220)$ crystals $(\mathrm{eV})$ given by formula

$$
\begin{aligned}
& 2.24 \times 10^{-7} \times d_{h k l}^{2} \times f_{h k l} \\
& \times\left\{\begin{array}{ll}
8 & \text { if } h, k, l \text { even and } h+k+l=4 n \\
4 \sqrt{2} & \text { if } h, k, l \text { odd } \\
0 & \text { otherwise }
\end{array}\right\}
\end{aligned}
$$

where $d_{h k l}$ the interplanar distance and $f_{h k l}$ the scatteringfactor values [13]. The differences between the $\Delta E_{\text {measured }}$ and $\Delta E_{\text {theoretical }}$ values are small, between $0.13 \mathrm{eV}(\mathrm{Y})$ and $0.30 \mathrm{eV}(\mathrm{Cr})$. This highlights that the experimental energy resolution of the beamline is close to the theoretical energy resolution.

Reproducibility. The energy reproducibility has been evaluated by measuring the quasi-elastic scattering peak of the incident beam from the sample using the crys-
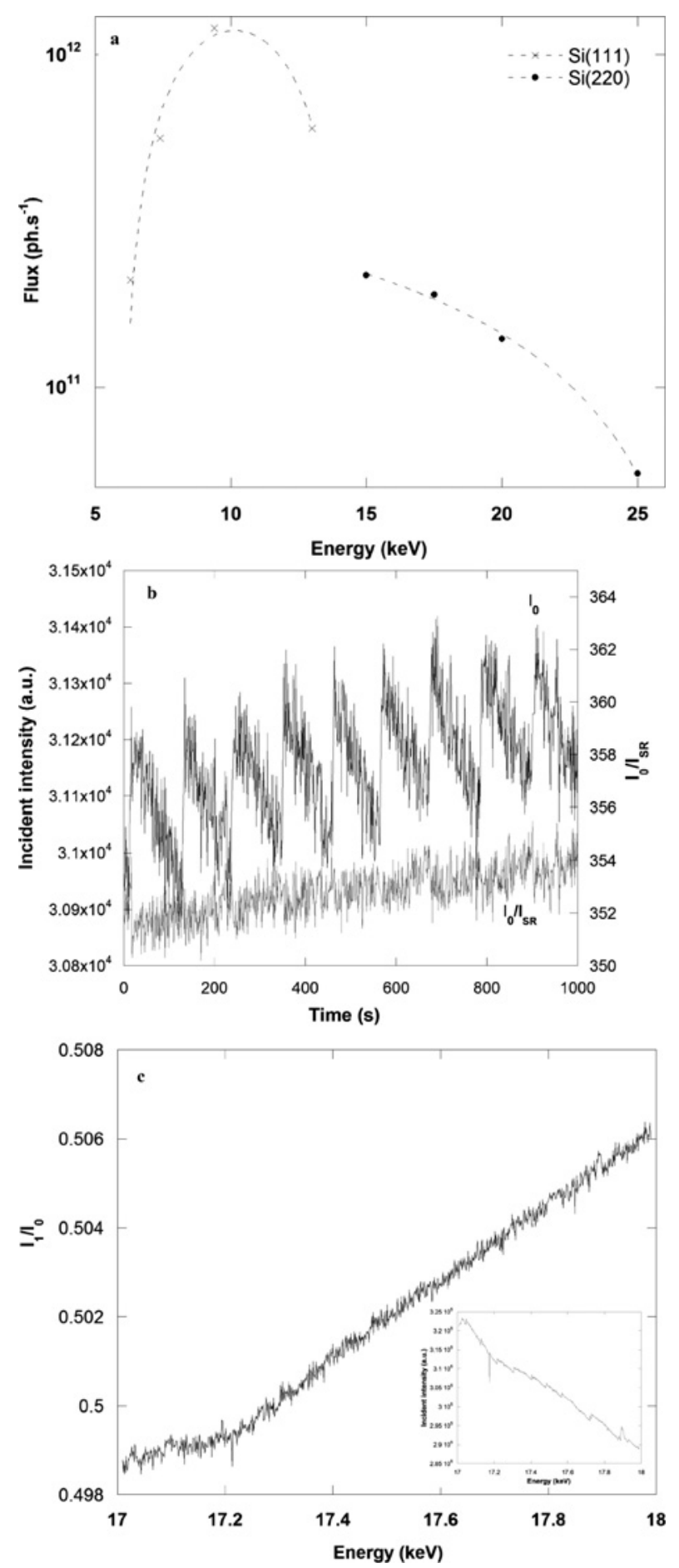

Fig. 2: (a) Measured flux of focused radiation with Si or Pt coated mirrors and $\mathrm{Si}(111)$ or $\mathrm{Si}(220)$ monochromator at $26 \mathrm{~m}$ from the source with a primary slit opening of $20 \times 2 \mathrm{~mm}^{2}$ and a machine current of $430 \mathrm{~mA}$. (b) Monochromatic X-ray beam intensity, $I_{0}$, as measured without any energy displacement, and normalized for the storage-ring current. During the $1000 \mathrm{~s}$ acquisition time, $I_{\mathrm{SR}}$ varies from 88.85 to $87.86 \mathrm{~mA}$. Measurement conditions: $1 \mathrm{~s}$ per point at the $32.513 \mathrm{keV}$ using $\mathrm{Si}(220)$ crystals $\left(\theta_{\mathrm{Bragg}}=5.4467^{\circ}\right)$. (c) $I_{1} / I_{0}$ ratio between 17 and $18 \mathrm{keV}$. Measurement conditions energy step $1 \mathrm{eV}$ and an integration time $1 \mathrm{~s}$, monochromator Si(220). Inset: $I_{0}$. 


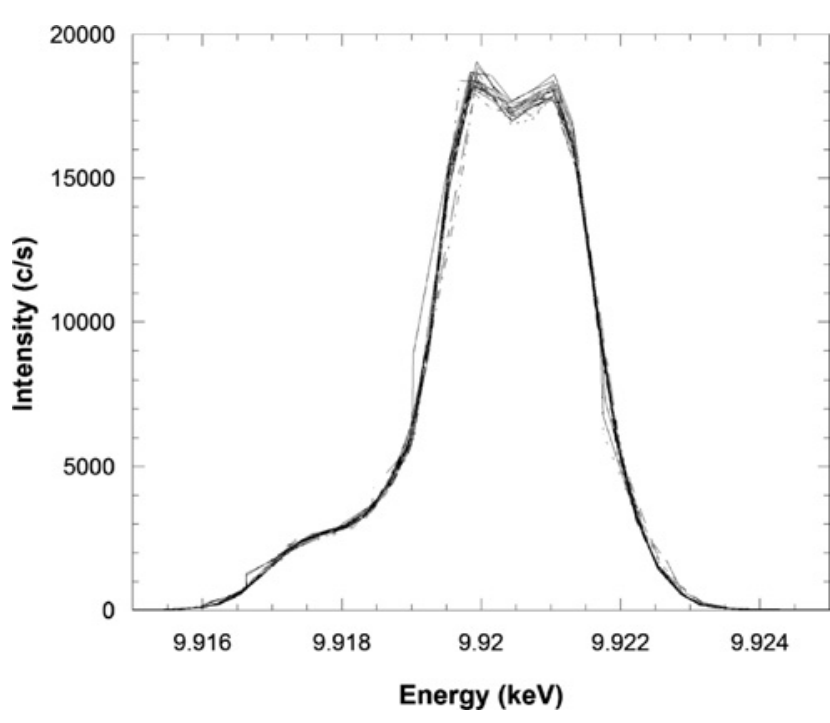

Fig. 3: 20 Spectra around the pseudo-elastic peak recorded using the crystal analyzer spectrometer during $55 \mathrm{~h}$. The energy is set at $9.92 \mathrm{keV}$.

tal analyzer spectrometer (see Sect. 2.3.3) (Figure 3). The measurements have been performed at $9.92 \mathrm{keV}$ using the $\operatorname{Si}(220)$ monochromator $\left(\theta_{\mathrm{Bragg}}=18.993^{\circ}\right), \operatorname{Si}(555)$ bent crystal analyzers $\left(\theta_{\text {Bragg }}=85.240^{\circ}\right.$ ) during $55 \mathrm{~h}$ (see Sect. 3.4). Among the 78 spectra recorded, 12 have been fitted by a Gaussian function. The energy reproducibility is $\pm 0.04 \mathrm{eV}$.

\subsubsection{Secondary optics}

In addition to the long mirrors and the monochromator that are present in the main optics hutch, a refocusing optics based on a set of two mirrors in the Kirkpatrick-Baez (KB) geometry was recently installed on the XAS end station. This extends the performances of the beamline towards the micrometric scale, by allowing X-ray fluorescence mapping characterizations as well as micro-XAS and micro-XRD measurements without losing to much flux in comparison to a collimated beam. In addition, it provides a mean to decrease the volume of analyzed materials and consequently the effective dose rate from highly radioactive samples.

The system which was designed by SOLEIL consists of two orthogonal trapezoidal Rhodium coated mirrors provided by ZEISS (Germany) that are positioned in the beam axis with two translation motorized stages and are oriented at a fixed grazing incidence angle of around $3 \mathrm{mrad}$ with two rotation stages. All stages with motors and encoders were provided by AXMO company (France). The first mirror reflects and refocuses the beam in the vertical plane and the second reflect and refocuses in the horizontal plane.

The micro-beam dimensions obtained are in agreement with the expected values of $10 \times 10 \mu \mathrm{m}^{2}$ for a flux around $10^{10} \mathrm{ph} / \mathrm{s}$ at $8 \mathrm{keV}$.

\subsection{XAS end-station description}

Two experimental stations are currently operational which are located in the second shielded hutch inside the central area of the beamline. The first end-station, which consists essentially in a high resolution diffractometer, is dedicated to XRD and WAXS measurements and will be discussed elsewhere. The second end-station, which is the object of this contribution, is principally dedicated to XAS measurements, but also transmission XRD measurements are regularly performed (separately or coupled to XAS).

\subsubsection{Sample environment}

The samples in their sample-holders can be fixed on a multi-axis manipulator provided by AZ-Systèmes (France) (Figure 4a) which is designed for high precision sample alignments or displacements along the X-ray beam. The sample manipulator consists in 8 complementary motorized stages: two horizontal translation stages perpendicular to the X-ray beam, two horizontal translation stages parallel to the X-ray beam, two vertical translation stages, and two rotation stages along the vertical and horizontal axes. The upper part of the multi-axis manipulator can be replaced by a specific stage for multi-position sample holders (Figure 4b) They have been developed for liquid samples [14] and adapted by the MARS beamline team for solid samples.

The sample holder for liquid samples (Figure 4c) consists of two subunits, forming two independent confinement barriers: the inner cell and the double confinement. The internal cell consists of a central part having three Teflon ${ }^{\circledR}$ cells (for three samples of $200 \mu \mathrm{L}$ each), two windows of kapton ${ }^{\circledR}$ (50 $\mu \mathrm{m}$ thick) and two plates of stainless steel. The tightness around each cell is ensured by a viton ${ }^{\circledR}$ seal. The double confinement can accommodate 4 internal cells. From either side of the internal cells are placed between two windows of $50 \mu \mathrm{m}$ thick kapton ${ }^{\circledR}$. This sandwich (kapton ${ }^{\circledR}$ window + internal cell + window kapton ${ }^{\circledR}$ ) is then trapped between two metal frames. The tightness is ensured by a flat HFPV (hexafluoropropylenevinylidene fluoride) seal placed on either side of the frame made of Teflon ${ }^{\circledR}$. The sample holder for solid sam- 

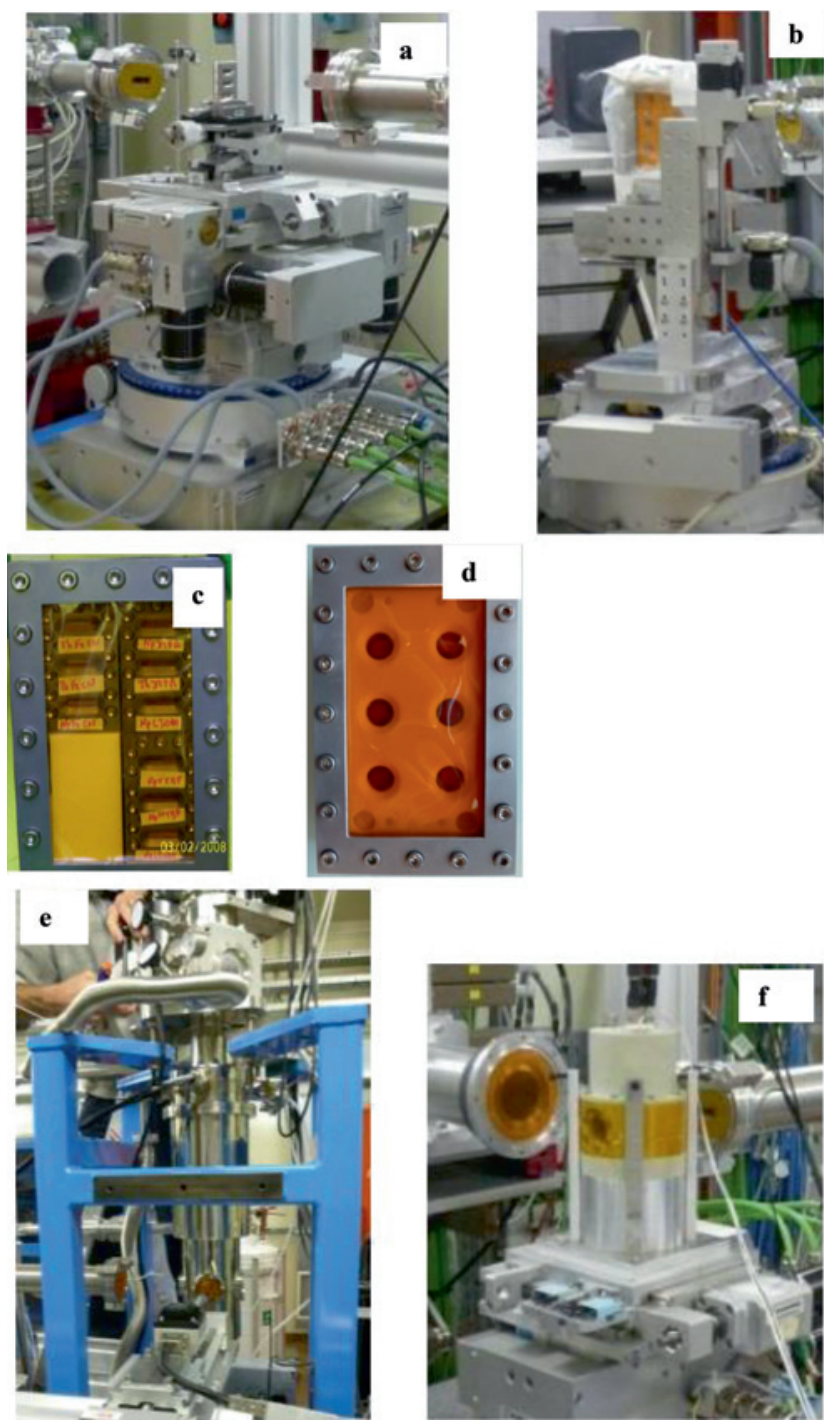

Fig. 4: Samples environment on MARS beamline: multiaxis manipulator (a), specific multi-position sample holder (b), liquid sample cell (c), solid sample cell and liquid $(200 \mu \mathrm{L})(\mathrm{d})$, cryostat (e) and spectro-electrochemical cell (f).

ples (Figure 4d) is based on the same concept i.e. the inner cell and the double confinement forming two independent confinement barriers. The sample sealed in the center of the kapton ${ }^{\circledR}$ tape as first containment barrier is placed within the Teflon ${ }^{\circledR}$ inner cell that can accommodate 6 samples. The double confinement is identical as that one used for sample holder for liquid samples.

Various sample cells are available to perform experiments under controlled conditions, e.g. liquid He cryostat, conditioned atmosphere vessel, electrochemical cell.

A specific cryostat (Figure 4e) is available to work at temperatures between $10 \mathrm{~K}$ to $298 \mathrm{~K}$ (liquid helium circulation). It was designed by SOLEIL staff with the collaboration of external expert users and manufactured by
Air Liquide (France) especially for the characterization of radioactive samples. This implies that the cryostat acts as a confinement barrier and that the internal pressure is below atmospheric pressure ( 200 mbars). The cryostat is composed of a main block which contains an internal sealed cryogenic chamber surrounded by a vacuum chamber containing a spiral pipe cooling circuit where the liquid helium flows. The samples are cooled down indirectly via the internal chamber. The cryostat is fixed on the first two axes of the manipulator and comprises two additional motorized stages for the sample positioning (a vertical translation and a rotation to position for fluorescence measurements) A special transfer module, which is attached on the upper part of the cryostat, is used for the sample transfer between the glove box (that is present in the storage room) and the cryostat without breaking the confinement. Specific sample-holders with double barrier confinement for contaminating samples have been developed and also sample-holders for liquids are foreseen.

Spectro-electrochemical cells are also commonly used on beamlines dedicated to the radionuclides speciation $[15,16]$. An innovative cell has been developed for the MARS beamline through the collaboration with the CEA Saclay. In our design, the sample volume can be very small $(<2 \mathrm{~mL})$, thereby reducing the amount of activity needed in experiments. The electrochemical cell insures the mandatory double confinement: it is made of a monobloc tank containing the solution and closed with a lid to which the electrodes are fixed, and an outer protective enclosure (Figure 4f). The cell, i.e. the internal cell and the external enclosure, are made of polyimide (as in kapton ${ }^{\circledR}$ ). The electrochemical part counts an $\mathrm{Ag} / \mathrm{AgCl} \mathrm{KCl}$ $3 \mathrm{M}$ as reference electrode (WPI), a homemade reticulated vitreous carbon as working electrode and $\mathrm{Ag}$ wire as auxiliary electrode in a separate compartment connected to the main compartment by a glass frit. The electrodes geometry ensures a minimized ohmic drop between the reference and working electrodes and provides a uniform distribution of current density and potential over the working electrode. These electrodes are screwed onto the top of the cell and sealed with epoxy glue. Each cover plate contains three tight connectors for cables and electrodes. XAS spectra can be collected in transmission and fluorescence modes.

The multi-axis manipulator is very flexible; it is therefore possible for users to install their own experimental setup. This is the case for example of a special furnace to perform XAS/XRD measurements at high temperatures (up to $1500^{\circ} \mathrm{C}$ ) on actinide molten salts samples that has been developed by CNRS Orléans [17]. 


\subsubsection{Detectors}

Different detectors are available depending on the techniques and/or scientific topics considered.

For XAS measurements in transmission mode, three intensity monitors (IM) are placed or not directly in the Xray beam. These are in-house devices (design by H. Hermange) which consist of specific chambers with kapton ${ }^{\circledR}$ windows, that are inserted in standard KF60 cross vacuum flanges, containing two Si photodiodes (active area: 10x20 $\mathrm{mm}^{2}$ ), provided by Hamamatsu Photonics (Japan),which are mounted on opposite vertical sides of the X-ray beam axis with faces parallel to the horizontal plane (Figure 5). The beam intensity is measured by collecting the photons scattered by the gas or other scattering element present in the chamber and adding up the currents generated by the diodes. The arrangement with two diodes allows avoiding possible signal drifts due to instabilities in beams' vertical position. The chambers are usually kept in air at ambient pressure on the whole X-ray energy range, but, alternatively to improve detection efficiency, a specific heavier gas (such as argon) can be used or a specific scattering foil can be inserted. Additionally, the gap between the two diodes can be increased or reduced down to $2 \mathrm{~mm}$. The sum of generated currents are transmitted to an amplifier (DLPCA-200 or DDPCA300 developed by FEMTO Messtechnik, Germany) which amplify and convert them into a voltage range of 0 to $10 \mathrm{~V}$. The typical intensity ranges from $10^{-6} \mathrm{~A}$ to $10^{-9} \mathrm{~A}$. The voltage to frequency transformation is ensured by a NOVA R\&D (USA) card within a NIM box $\left(0 \mathrm{~V} \sim 0 \mathrm{~Hz}\right.$ and $10 \mathrm{~V} \sim 10^{6} \mathrm{~Hz}$ ) which is then provided to a National Instruments counter card (USA).

XAS spectra in fluorescence mode (to measure diluted or thick samples) can be collected using a 13-element HighPurity germanium solid state detector (SSD) provided by EG\&G ORTEC (USA) or a mono-element $80 \mathrm{~mm}^{2}$ silicon drift detector (SDD) provided by KETEK (Germany). These two detectors have respectively $\sim 250 \mathrm{eV}$ and $\sim 150 \mathrm{eV}$ energy resolutions at $6.9 \mathrm{keV}$. Data processing is provided by a fully digital multi-channel XIA LLC DXP-XMAP modules
(USA). The SDD detector is used in particular in association with the crystal analyzer spectrometer (see below).

The X-ray beam can be directly inspected by using specific X-ray cameras that have been developed by SOLEIL's Detectors group [18]. These devices are essentially composed by YAG:Ce X-ray scintillators connected to commercial CCD cameras (provided by BASLER, Germany) with appropriate objective lens. Two cameras are dedicated to inspect the beam in the standard mode (with a resolution $14.8 \mu \mathrm{m}$ ), whereas an additional camera is dedicated to inspection of microbeam (with a resolution of $0.654 \mu \mathrm{m}$ ). Other 2D detectors, such as an image plate detector or a CCD camera (both by Marresearch, Germany), are available respectively directly on the beamline or via the SOLEIL detector pool to perform XRD-XAS coupling measurements.

\subsubsection{Crystal analyser spectrometer}

Besides the standard solid state detectors, a crystal analyzer spectrometer (CAS) is also available on the beamline to perform high-energy resolution X-ray fluorescence detection.

Fluorescence detection is classically achieved with SSD. This kind of detection however presents some limitations related to its limited energy resolution and possible saturation. Thus, in case of analyses on samples in which the element of interest is diluted respect to a highly scattering and/or fluorescing matrix or where, other elements in the sample present $\mathrm{X}$-ray fluorescence lines that overlap with the one of interest, this standard mode of detection is not possible. SSD is in particular not suitable in the specific case foreseen on MARS of measurements on highly irradiating $\gamma$-emitter samples. Indeed, in this case the natural emission of this type of samples can more easily overlap with the excited emission lines of interest and, most of all, can quickly saturate and even damage the detector. A way to overcome these limitations, can be achieved using a crystal analyzer spectrometer (CAS).
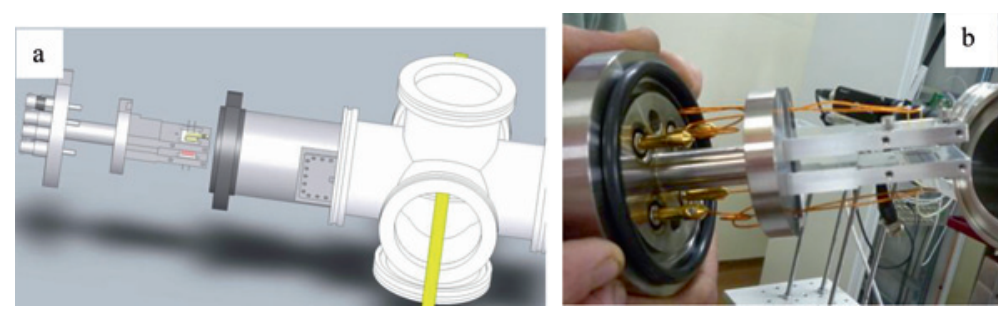

Fig. 5: Views of the specific double-diode intensity monitors: drawing (a) and picture (b). 


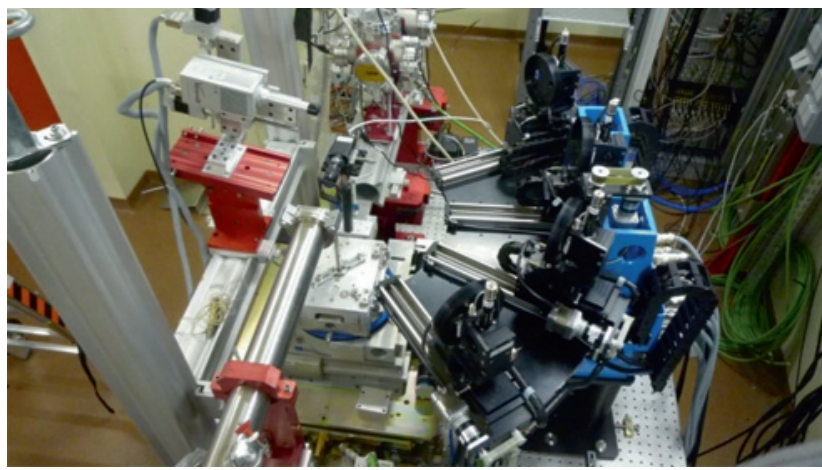

Fig. 6: View of the crystal analyzer spectrometer on the MARS beamline.

The spectrometer is a 4-crystal spectrometer adapted from the 5-crystal one installed on BM30B/CRG-FAME beamline at the ESRF $[19,20]$. The lower number of crystals was required because of the limited place around (KB system and in some case shielding around the sample) (Figure 6). The design and manufacturing were principally carried out by FAME's technical team (Eric Lahera and William Del Net, OSUG, Grenoble, France). The spectrometer is based on the Johann-type geometry which consists of spherically bent crystals associated with a detector (usually a SDD but 2D hybrid pixel detector or a photomultiplicator can also be used) positioned just above the sample. Each crystal has two translations along y and $\mathrm{z}$ axis and two rotations to adjust the verticality and normality of the crystal. Only the translations are used during the energy scan. Spherically bent Si crystals with $0.5 \mathrm{~m}$ bending curvature [21] with different orientations are available on the beamline.

Due to the achieved energy resolution of the spectrometer, high energy resolution fluorescence detection (HERFD) XAS can be performed. Furthermore other spectroscopic techniques are also available such as X-ray Emission Spectroscopy (XES), Resonant Inelastic X-ray Scattering (RIXS) and X-ray Raman Scattering (XRS) which is the energy loss version of XAS.

\section{Performances and results}

This paragraph presents a selection of experiments carried out with external users of SOLEIL to highlight the performance of the beamline according to the different possible configurations, i.e. standard XAS experiments using the Ge 13-element SSD or the crystal analyzer spectrometer for HERFD-XAS, XES and XRS measurements.

As it was said in the introduction, XAS is an established technique for speciation of actinides or other ra- dionuclides containing systems, addressing various topics related to environmental and biological investigations as well as the entire nuclear fuel cycle, since the preparation of the nuclear fuels, their use inside nuclear plants to the reprocessing of spent fuels and the storage of nuclear wastes. This is illustrated here by experiments on the uranium speciation in mine tailings, the speciation of neptunium in highly diluted solutions, the uranium chelation with extracting molecules and the in-situ reduction of uranium reduction (Sect. 3.1), as well as the studies of the structural components and material fuel claddings and those on the nuclear fuel itself (Sect. 3.2).

\subsection{Environmental studies and nuclear fuel chemistry}

Actinides are of minor abundance in the environment and yet are important contaminants mainly associated to anthropogenic activities linked either to civil or military nuclear activities. XAS can be a complementary tool in addition to other techniques to assess the speciation of actinides in environmental or biological samples at the molecular level.

A first example of environmental studies on actinides performed on the beamline concerns the study of the uranium speciation in mill tailings from the Gunnar mine.The Gunnar uranium mine (Saskatchewan, Canada) operated from 1955 to 1963, resulting in the discharge of about 4.4 million tons of mill tailings in the vicinity of the mine [22]. Toxic heavy metals and radionuclides (e.g. uranium) contained in tailings may contaminate water, soil and plants near the disposal sites [23, 24]. Uranium mobility and bioavailability in the environment is mainly governed by its speciation, more specifically its oxidation state, as $\mathrm{U}(\mathrm{IV})$ is much less soluble than $\mathrm{U}(\mathrm{VI})$. Uranium oxidation state was probed by XANES spectroscopy through a depth profile of Gunnar mill tailings, with U concentrations ranging from 60 to $740 \mathrm{ppm}$. U $L_{\mathrm{III}}$-edge XANES spectra were measured at room temperature, in fluorescence-yield mode using the 13-element Ge SSD and under a $\mathrm{N}_{2}$ flux to minimize uranium oxidation. Five to 15 spectra were merged depending on the U concentration. Energy positions and the multiple-scattering feature characteristic of the axial oxygen atoms from the uranyl $\left(\mathrm{UO}_{2}{ }^{2+}\right)$ group [25] indicated that uranium mainly occurs as $\mathrm{UO}_{2}{ }^{2+}$ in all samples investigated (Figure 7). Linear combination fitting of the spectra with pure $\mathrm{U}(\mathrm{IV})$ and $\mathrm{UO}_{2}{ }^{2+}$ references showed that tailings contained from $73 \%$ to $98 \%$ of $\mathrm{UO}_{2}{ }^{2+}$ phases. Additional analyses indicated that uranium mainly occurs as uranyl complexes sorbed onto iron-bearing com- 


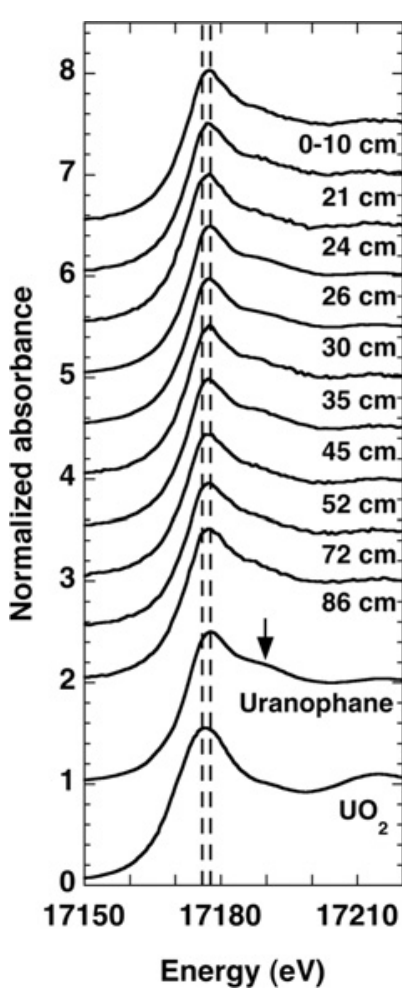

Fig. 7: $U L_{\text {III }}$-edge XANES spectra of Gunnar mill tailings compared to $\mathrm{U}(\mathrm{IV})$ standard $\left(\mathrm{UO}_{2}\right)$ and the $\mathrm{UO}_{2}{ }^{2+}$ standard (uranophane). Vertical dashed lines indicates white line maxima of the $\mathrm{U}(\mathrm{IV})$ and $\mathrm{UO}_{2}{ }^{2+}$ references [26]. Vertical arrow shows the resonance feature above the absorption edge characteristic of the uranyl moiety. Copyright 2013 American Chemical Society.

pounds [26]. Changes in water conditions (e.g. $\mathrm{pH}$ or presence of ligands that readily complex uranium) may therefore release uranium through dissolution or desorption processes and enhance its transport at the Gunnar site.

A second example of environmental and toxicological impact of the actinide elements performed on the beamline concerns speciation study of these elements in natural systems or accumulated in living organisms (including humans). The general goal of the researches conducted at the Nice Chemistry Institute and at the Orsay Nuclear Physics Institute is to better understand the chemical mechanisms of dispersion and accumulation in various environmental compartments (more specifically the hydrosphere), in the biotope or in humans of the low level anthropogenic radioactive nuclides due to early nuclear weapon tests (performed in the sixties), to nuclear industrial accidents (such as Chernobyl and Fukushima Dai-ichi) or to potential terrorist threat.

In order to go beyond the inventory description, a molecular speciation approach, such as possible with $\mathrm{XAS}$, is compulsory. Environmentally or biologically available levels of contaminations in non-specifically exposed regions are far too low to allow any speciation spectroscopic technique to take place. In order to overcome this difficulty, samples have to be doped in the laboratory to the ppm level (around $1 \times 10^{-5} \mathrm{M}$ for actinide elements). Although this range of concentrations is evidently not fully representative of the environmental conditions, it is an intermediate and compulsory step between the laboratory scale chemistry and the environmental levels. We present here as an example the first transuranic solution measured on the beam line in December 2012. This measurement has been performed in the standard cells described in Sect. 2.3.1 below the exemption limit of 237-Np. The spectrum corresponds to a model solution of $\mathrm{Np}(\mathrm{V})$ carbonate in pure water. Qualitatively, the oxo contribution evidently occurs at $R+\Phi=1.2 \AA$ while the carbonate oxygens in the equatorial plane occur at $R+\Phi=2.0 \AA$. The significant peak at $R+\Phi=3.7 \AA$ is the fingerprint of the carbonate distal oxygens in the multiple scattering mode. A quantitative adjustment of the data will be presented elsewhere.

In a near future, it is foreseen to probe higher diluted samples by improving the design of the cells with optimized X-ray path length and thus X-ray fluorescence signal. This type of cells for radioactive samples is currently under development with the aim to reach the ppm level. This is would be to our knowledge the first attempt to measure directly the molecular speciation of actinides in seminatural or -biological samples at such a low level of concentration.

Additionally, XAS studies on uranium-protein systems have been performed on the beamline which will be not presented here for brevity. These have mainly concerned the investigation of uranium or thorium interaction with a protein (osteopontin) involved in the bone system (see details in ref. [27]).

In the field of nuclear waste management, spent nuclear fuels can be reprocessed to separate specific nuclides (such as $U$ and transuranian elements) from highlevel radioactive wastes. In general, processes are based on liquid-liquid extraction, using a selective organic extractant. However, the mechanisms of ions transfer from the aqueous nuclear waste solutions to the organic phase are complex and poorly understood [28]. The structures of the extracted species are often not known, the formation of oligomeric species or aggregation of the extractant can occur in the organic phase, rendering the interpretation of the results rather difficult. Therefore, thorough knowledge of interactions at the molecular scale between ions and extracting molecules, obtained via techniques such as XAS, is needed to better understand the complexation mechanisms involved in the extraction processes. 

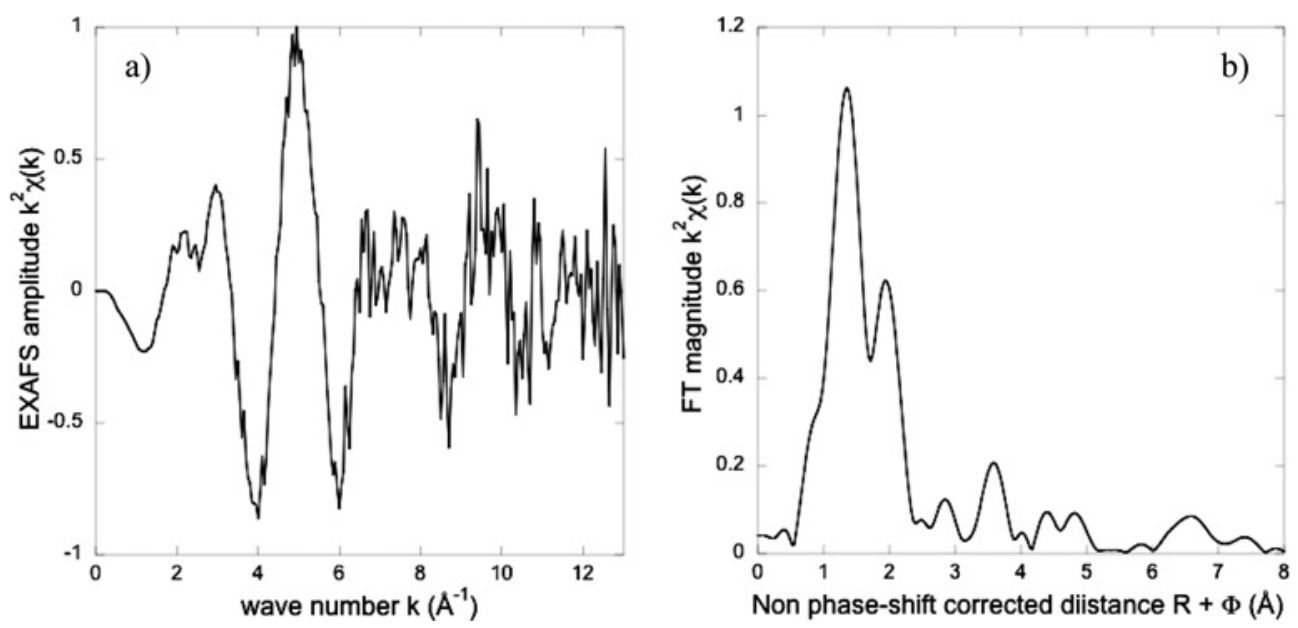

Fig. 8: (a) Average EXAFS spectrum of $\mathrm{Np}(\mathrm{V})$ carbonate at $5 \times 10^{-5} \mathrm{M}$ in pure water (total accumulation time $=600 \mathrm{~min}$ ). Calculated average noise in $k^{2}$ is 0.0133 from back Fourier transform after $R+\Phi=6 \AA$. (b) Corresponding Fourier transform up to $k=11 \AA^{-1}$.
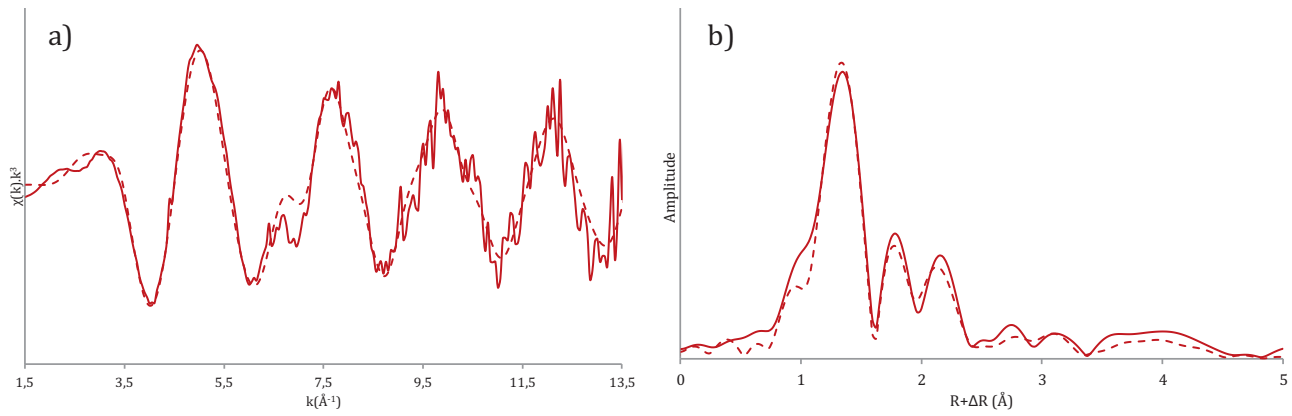

Fig. 9: (a) EXAFS data fitting of $\left[\mathrm{UO}_{2}\left(\kappa 2-\mathrm{NO}_{3}\right)_{2}(\mathrm{TEPA})\right]$. (b) Fourier Transform of EXAFS spectrum.

An example of this kind of investigation that has been carried out on the MARS beamline concerns the study of $\left\{\mathrm{U}(\mathrm{VI}) \mathrm{O}_{2}{ }^{2+}\right\}$ organic-phase complexes obtained after uranium extraction from an acidic aqueous phase, by $\mathrm{R}_{2} \mathrm{NOC}\left(\mathrm{CH}_{2}\right)_{n} \mathrm{CONR}_{2}$ diamide derivatives.

In a first step, XAS measurements at uranium $L_{\mathrm{III}^{-}}$ edge and EXAFS analysis were performed on uranyldiamide solid complexes with short chains on the nitrogen atoms. Samples were both in liquid and solid form containing repectively $5 \times 10^{-2} \mathrm{M}$ and $0.18 \mathrm{mg}$ of uranyl. These have been selected since their structures were already determined by single-crystal X-ray diffraction and other complementary techniques [29].

In Figure 9, the EXAFS and corresponding Fourier Transform of the $\left[\mathrm{UO}_{2}\left(\kappa 2-\mathrm{NO}_{3}\right)_{2}(\mathrm{TEPA})\right] \infty$ complex (TEPA $=$ Tetraethylpimelicamide) is presented as an example.

A reasonably good fit was obtained with distances in agreement with that of the crystal structure and coherent Debye-Waller factors $\left(\sigma^{2}\right)$, with $2 \mathrm{O}(\mathrm{yl})$ at $1.77 \AA$ and $\sigma^{2}=0.002 \AA^{2} ; 2$ (diamide) at $2.32 \AA$ and $\sigma^{2}=0.0074 \AA^{2}$;
4 O(nitrate) at $2.50 \AA$ and $\sigma^{2}=0.0077 \AA^{2}$; $2 \mathrm{~N}$ (nitrate) at $2.95 \AA$, and $\sigma^{2}=0.0096 \AA^{2}$.

In a second step, measurements have been performed with the extracted complexes in the organic phase containing more complicated diamides to further evaluate the impact of the diamide structure on the uranium coordination mode. The fitting results obtained on the solid model compounds were used as starting point for the XAS analysis of these additional liquid samples. In this case, it was observed that the uranium coordination sphere in the organic phase-extracted complexes was identical to that of U(VI) model complexes, obtained with $\mathrm{N}$-short chain diamides (detailed results will be published elsewhere).

A last example concerns a study of electrochemical systems using the cell described in paragraph 2. Because of their electronic structure, Actinides (An) may be found in various oxidation states, with the $\mathrm{AnO}_{2}{ }^{+}$and $\mathrm{AnO}_{2}{ }^{2+}$ species at the $+\mathrm{V}$ and $+\mathrm{VI}$ states, respectively. The environmental behavior of actinides is controlled by their oxidation state but also by the presence or absence of ligands. Actinides in their reduced form are generally found in the 


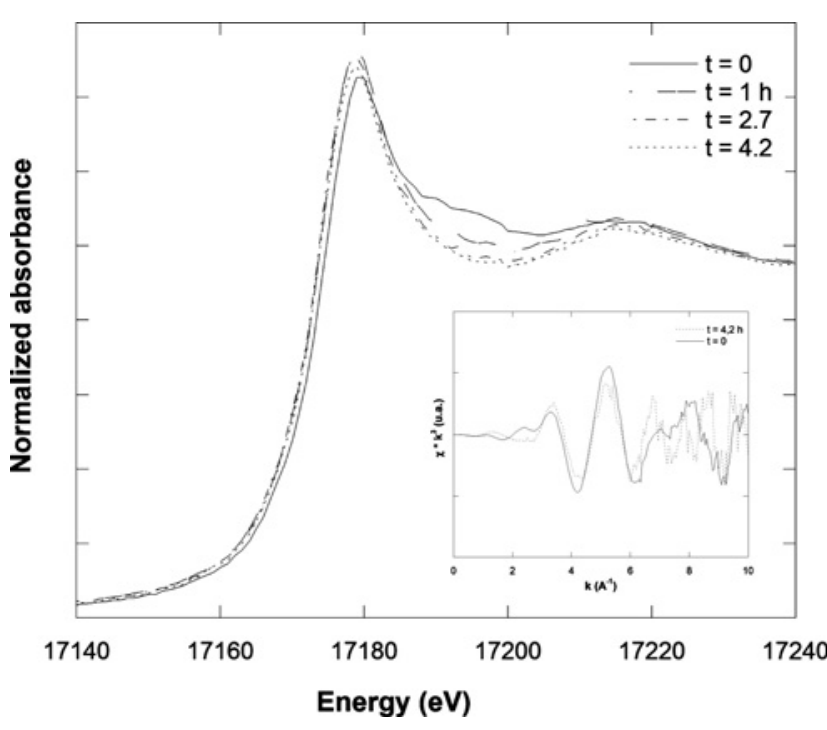

Fig. 10: Reduction of a solution of uranyl(VI) in the presence of paracoumaric acid. Evolution of the XANES and EXAFS signals as a function of reaction time at uranium $L_{\mathrm{III}}$-edge.

solid state $\left(e . g . \mathrm{UO}_{2}(\mathrm{~s})\right)$ or colloidal phases. They can also be complexed with ligands such as natural organic matter, resulting in greater mobility and bioavailability. The stability and stoichiometry of these complexes can be assessed by determining the molecular environment of the actinide, and thus constraining the complex structure. This however, requires that the complex be kept in a stable form, a challenge especially for complexes of reduced, redoxsensitive An. This limitation can be overcome by using a setup in which An can be reduced on the beamline, immediately prior to XAFS measurements. A first experiment was conducted on the MARS beamline to determine the local environment of the reduced form of uranium (+IV) complexed with the paracoumaric acid $\left(\mathrm{C}_{9} \mathrm{H}_{8} \mathrm{O}_{3}\right)$, simulating humic acids. $\mathrm{U} \mathrm{L}_{\mathrm{III}}$-edge spectra are collected in fluorescence mode on a uranyl solution at $1 \mathrm{mM}(238 \mathrm{ppm})$ using the electrochemical cell to reduce uranium in-situ, while following the progress of the reaction (Figure 10). In oxidizing conditions, 8 scans, with respectively $5000 \mathrm{c} \mathrm{s}^{-1}$ and $45000 \mathrm{c} \mathrm{s}^{-1}$ before and after the edge, are necessary to obtained good quality data. While in reducing conditions, the presented data contain one spectrum. The data have been analyzed and the results highlight the formation of an uranium (IV) complex with paracoumaric acid, thus preventing the formation of uranium dioxide $\mathrm{UO}_{2}(\mathrm{~s})$. Adjustment of the EXAFS spectrum showed, on the one hand, the monovalent coordination mode of the carboxyl groups and, on the other, that $70 \%$ of the initial uranyl had been reduced in-situ.

\subsection{Nuclear material}

One of the main goals of research in nuclear energy is to improve the economic and safety performance of nuclear reactors. The most challenging research concern nuclear fuels performance and particularly how irradiation point defects and fission products can affect the behaviour and integrity of fuel cladding materials. In the following, two examples of experiments performed using the CAS spectrometer on nuclear materials will be discussed.

Zirconium, with its properties of very low thermal neutron capture cross section, good water corrosion resistance for in-service conditions $\left(\sim 350^{\circ} \mathrm{C}\right)$, stability of mechanical properties even under irradiation up to high doses, is widely used for cladding and structural materials in the light water reactors' core. Improvements of properties for superior cladding materials, mainly with regard to corrosion resistance but also to mechanical properties under irradiation (creep, growth), has led metallurgist and fuel designers to join their efforts. An optimized microstructure has especially led to propose a new $\mathrm{Zr}-1 \% \mathrm{Nb}-\mathrm{O}$ alloy, in weight $\%$, (for example $\mathrm{M}^{\mathrm{TM}}$ for Areva) in replacement of Zircaloy-4 (Zy-4, a Zr-1.3\%Sn-0 alloy). Under irradiation, point defects are created and agglomerated as loops in specific planes, thanks to the strong anisotropic behaviour of $\mathrm{Zr}$, hexagonal close-packed crystallographic structure. At high irradiation doses, $\langle c\rangle$ vacancy loops located only in basal planes could be observed. Those $\langle c\rangle$ vacancy loops are responsible of free stress deformation under irradiation called growth. At the same time, precipitates always present in these Zr-based alloys (volume fraction $\sim 0.5 \%$ ) are also affected by irradiation, leading to partial or total dissolution and/or amorphization, or re-precipitation phenomena. Obviously, precipitation evolution under irradiation has large influence on mechanical properties and also on their corrosion behaviour in service conditions. Thus, transmission XRD, transmission electronic microscopy and small angle neutron scattering measurements preformed on $\mathrm{Zr}-1 \% \mathrm{Nb}-\mathrm{O}$ before irradiation evidence native $\beta$-Nb particles in the body-centred cubic crystallographic structure (space group: Im-3m) [30]. After neutron irradiation, the native $\beta$-Nb particles remain fully crystalline even after 6 PWR annual cycles of irradiation. They also evidence statistical information on the radiation-enhanced precipitation of $\beta$ - $\mathrm{Nb}$ needles of few nanometres in diameter. These needle-like precipitates remain in the same bcc crystallographic structure with a larger lattice parameter. This $\mathrm{Zr}-1 \% \mathrm{Nb}-\mathrm{O}$ alloy demonstrate a large enhancement on corrosion resistance behaviour (factors 3 to 4) and mechanical properties (factors 2 to 3 ) for creep and growth under neutron irradia- 


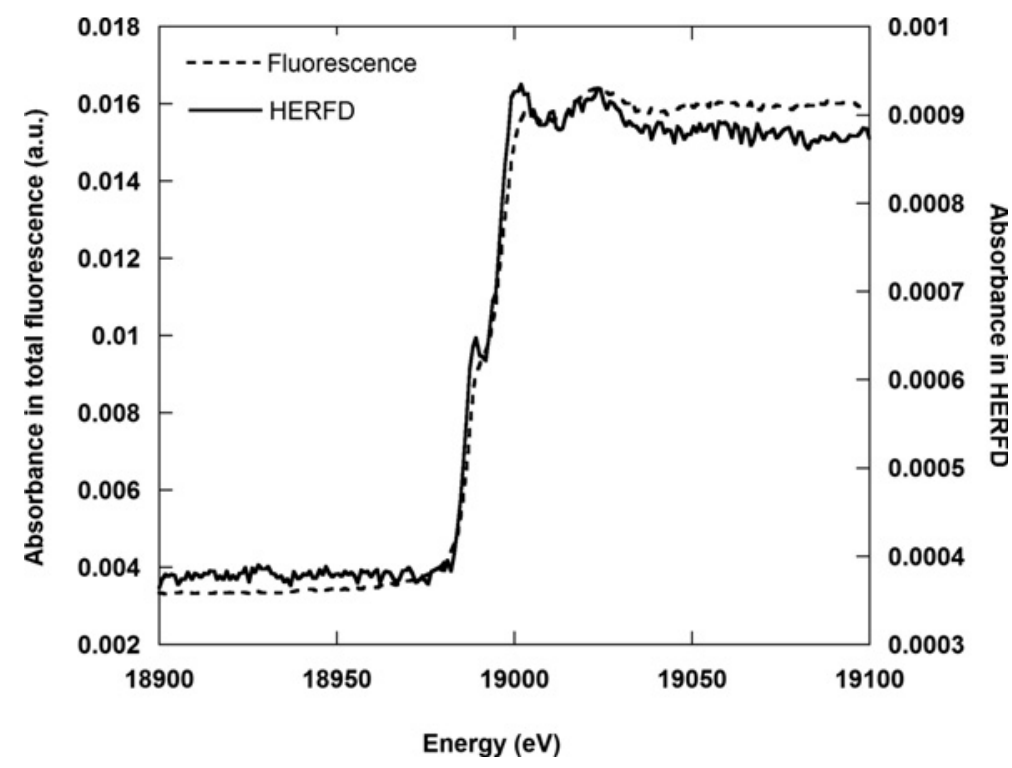

Fig. 11: $\mathrm{Nb}$ K-edge XANES of Zr-1\% Nb alloy (model alloy fabricated by CEA: Van Arkel Zr alloy) collected in total fluorescence yield using a Vortex EX-90 silicon drift detector (SDD) and in high energy resolution fluorescence detection using the crystal analyzer spectrometer (CAS).

tion in the in service condition after 5 PWR annual cycles or irradiation [31]. XAS measurements will allow to analyze the involvement of point defects and their equilibrium population in the vicinity of $\mathrm{Nb}$ absorber atoms, and then radiation-induced microstructural and microchemical changes in precipitates, as a function of irradiation conditions and materials composition.

In our experiment, we focus on $\mathrm{Zr}-1 \% \mathrm{Nb}$ alloy (model alloy fabricated by CEA,Van Arkel Zr based alloy with weight chemical composition: $1 \% \mathrm{Nb}$; 500ppm Fe, $100 \mathrm{ppm} 0 ; 2.2 \% \mathrm{Hf}, \mathrm{Zr}$ balance) reference compound i.e. without irradiation to determine the $\mathrm{Nb}$ local order. The difficulty, here, is to probe an element ( $\mathrm{Nb}$, atomic no. Z) included in another (Zr, atomic no. Z-1) which dominates the fluorescence signal. Nb K-edge XANES spectra (Figure 11) are collected both in total fluorescence and HERFD. Data are collected using the Vortex Ex-90 ${ }^{\circledR} \mathrm{SDD}$ and the CAS equipped with one Si spherically bent ( 888 reflection) crystal . The overall average energy bandwidth of the X-ray spectrometer is $9.0 \mathrm{eV}$. 11 scans are merged and normalized. This experiment has a double interest. The first one is to probe a diluted element ( $\mathrm{Nb}$ at $1 \%$ ) in a fluorescent matrix. The second more technical interest is to highlight the interest of such measurements for these materials. The background on CAS spectrum is very low, only due to photons scattered (not diffracted) by the crystals. Inversely, the background on SSD spectrum is higher. Independently from statistical considerations, from these measurements, two observations can be made: (i) CAS measurements give a better resolution of the threshold structure (see for example ref. 32 for a recent explanation of this phenomenon) and (ii) saturation of the detector has been overcome to obtain better quality data which will be useful in case of irradiated compounds. HERFD data have been analyzed and preliminary results show that $\mathrm{Nb}$ is in its metallic form $\beta$ $\mathrm{Nb}$. Irradiated materials can now be characterized using such technique.

Nuclear fuel behaviour and its interaction with cladding materials strongly depend on the chemical stability of fission products and their evolution during the irradiation process. These products, such as Mo, can be found in several chemical states as metallic or oxides precipitates as well as oxides dissolved in the $\mathrm{UO}_{2}$ matrix, depending on the partial oxygen potential. To understand the fuel behaviour, one has to determine the correlation between the fuel stoichiometry as a direct fingerprint of the oxygen potential and the chemical states of fission products. Indeed, the fuel stoichiometry affects its thermal, chemical, and physical properties during irradiation and the chemical states of fission products modify their reactivity with the cladding material. XAS is a key technique to obtain such kind of information, but the very high radioactivity of irradiated fuels ( $>200 \mathrm{MBq} / \mathrm{mg}$ ) limits the sample size that can be investigated with this technique in conventional transmission or fluorescence mode. Moreover, the impossibility to isolate the fluorescence line of one element because of the high background interference (radioactivity and fluorescence coming from other elements) as well as 


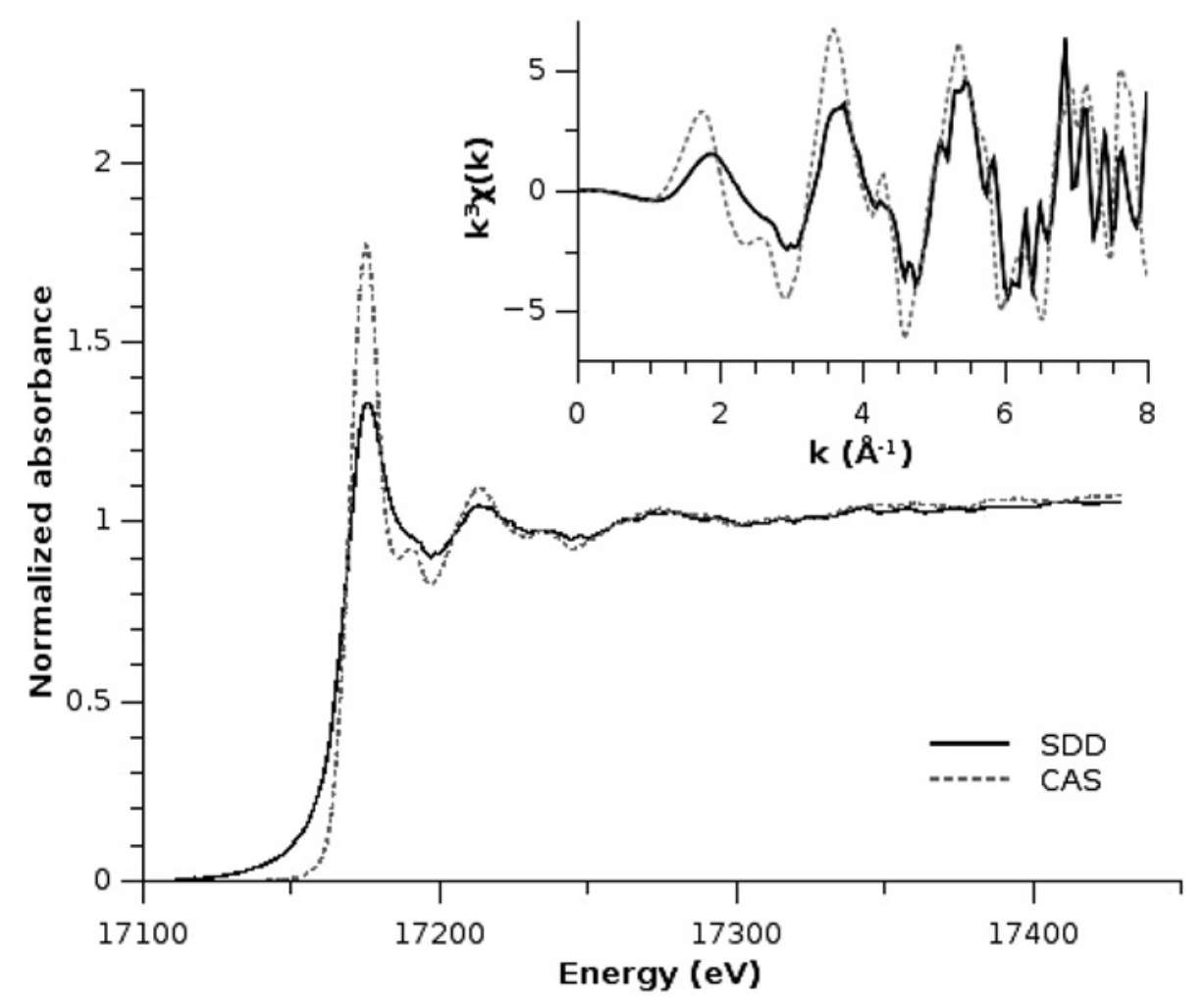

Fig. 12: $U L_{\text {III }}$-edge XANES collected in total fluorescence yield (SDD) and in high energy resolution fluorescence detection using the crystal analyzer spectrometer (CAS) on doped nuclear fuel. Insert: $k^{3} \chi(k)$ EXAFS spectrum collected using both methods.

the presence of Bragg peaks due to the X-ray diffraction on the high crystallized nuclear fuel, systematically induce large pollution on fluorescence spectra. For example, Degueldre et al. have developed a new approach in order to overcome the former difficulty using micro-XAS on very small fragment of spent fuel $[33,34]$. Nevertheless, their encouraging results are limited to high concentrated elements such as actinides and could not be easily applied to more diluted fission products. To overcome all of these difficulties, XAS measurements in fluorescence mode using CAS are mandatory. A first step towards the investigation of irradiated fuel is to consider the so-called virgin SIMFUEL which is a nuclear fuel doped with eleven stable fission products (Ba, Ce, La, Sr, Mo, Ru, Rh, Pd, Y, Nd and $\mathrm{Zr}$ ). The concentration of each element was adjusted to match to those measured in irradiated fuel [35] and is about 0.51 at. \% for Mo. The investigation of this fission product is very challenging because its concentration is very low and it is not distributed uniformly on the sample.

The experiment described herein was thus focused on the investigation of the Mo $K$-edge as well as the uranium $L_{\text {III }}$-edge of SIMFUEL.

The XANES spectra have been collected simultaneously in total fluorescence with a Vortex-90-EX ${ }^{\circledR}$ silicon drift detector and in HERFD with the CAS. The CAS was positioned to follow the $L_{3} M_{5}\left(L \alpha_{1}\right)$ emission line at $13.618 \mathrm{keV}$ for the $\mathrm{U} L_{3}$-edge and the $\mathrm{KL}_{3}\left(K \alpha_{1}\right)$ emission line at $17.480 \mathrm{keV}$ for the Mo $K$-edge. The CAS was used in combination with a Ketek AXAS-M1 ${ }^{\circledR}$ silicon drift detector and was respectively equipped with 2 spherically bent $\mathrm{Si}(110)$ crystals using the (880) reflection and with 4 spherically bent $\mathrm{Si}(111)$ crystals using the (888) reflection for $U L \alpha_{1}$ and Mo $K \alpha_{1}$ fluorescence lines, respectively. The total resolution of the HERFD spectra (including CAS and beamline resolution) have been measured to be around $10 \mathrm{eV}$ for both edges. Two spectra at $\mathrm{U} L_{\mathrm{III}}$-edge and eight at Mo K-edge are collected with an acquisition time of 55 min and merged (Figs. 12 and 13).

As expected using CAS, the XANES structure is better resolved than in total fluorescence detection. Moreover, the Mo signal has been successfully measured despite of its inhomogeneous distribution and its low concentration (0.51 at. \%). Consequently, one can positively expect that the observation of slight modifications on the chemical state of actinide elements and of low concentrated fission products by XAS will be possible also on spent nuclear fuels in the near future on the MARS beamline. 


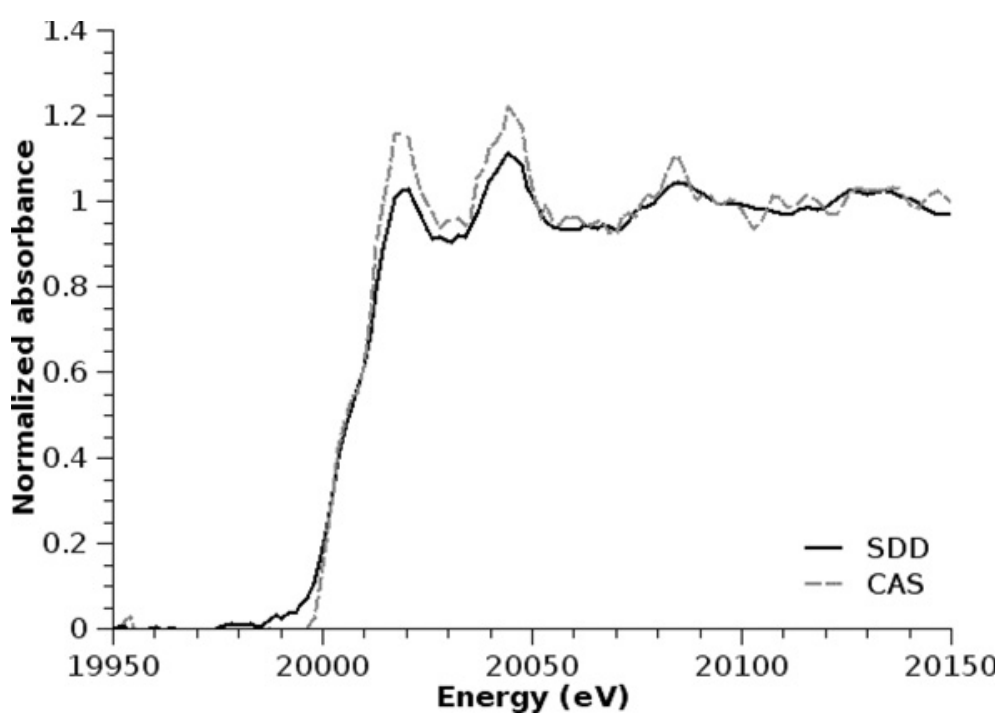

Fig. 13: Mo $\mathrm{K}$-edge XANES collected in total fluorescence yield (SDD) and in high energy resolution fluorescence detection using the crystal analyzer spectrometer (CAS) on doped fuel sample.

\section{Additional possibilities: Inelastic scattering experiment}

The X-ray Raman scattering (XRS) is the energy loss version of XAS. The incident X-ray beam is inelastically scattered (Compton scattering), a part of the incident photons energy is transferred to the sample through electronic transitions. Under certain experimental conditions, the same XAS features are seen in the Compton scattering profile peak when the transferred energy equals the binding energy of the probed element [36, 37]. The use of hard X-ray with a large penetrating power can offer then a good alternative to soft X-ray XAS to probe low energy edges in samples with high absorbing environmental set-up such as confinements in case of radioactive samples, cryostat, high-pressure, high-temperature cells... Reversingly, the disadvantage of this process is the very weak cross-section compared to the photo-electric effect.

The aim of the experiment is to collect $\mathrm{C} K$-edge XANES spectrum of a radioactive sample using XRS in order to obtain bulk information which is not possible using soft X-ray XAS. However, given that the beamline is dedicated to XAS and not to inelastic X-ray scattering (IXS), a second aim of these inelastic measurements is also to validate the setup using the CAS. ThFe $(\mathrm{CN})_{6} \cdot \mathrm{nH}_{2} \mathrm{O}$ has been selected for this test because it is an ideal case for low energy edge analysis since all the ligands are equivalents. The actinide hexacyanoferrate family in general has also demonstrated to be of interest for the investigation of possible covalency in actinide bonding [38].
Initially, the carbon $K$-edge of glassy carbon has been collected using one $\mathrm{Si}(555)$ crystal with a resolution of $2.2 \mathrm{eV}$ at $9.92 \mathrm{keV}$ (Figure 14) to validate our experimental approach. The Bragg angle equals $85.25^{\circ}$ at this energy and for this orientation, i.e. very close to $90^{\circ}$. Total energy resolution is then limited to the intrinsic resolution of the analyzer, the energy spreading due to the Johann's geometry being minimum, the incident photon bandwidth (due to the monochromator) and the vertical size of the beam on the sample. The total energy resolution has been measured to $2.2 \mathrm{eV}$, quite far from the theoretical expected value probably due to microstrains in the silicon bent wafer as it has been already observed on bent crystal with the same radius of curvature [20].

The energy transfer is scanned through the carbon $K$-edge by changing the incident energy on the sample from 10.190 to $10.250 \mathrm{keV}$. A helium bag is installed to limit air absorption on the source-to-crystal and crystal-todetector X-ray paths. 21 spectra are collected and merged for a total acquisition time of $16 \mathrm{~h}$. The XANES spectrum presents a peak in the pre-edge at $286 \mathrm{eV}$ corresponding to $1 \mathrm{~s} \pi^{*}$ transition while features present at energies above $293 \mathrm{eV}$ corresponds to the $1 \mathrm{~s} \sigma^{*}$ transitions [39]. Similar measurements have been previously performed on dedicated IXS beamlines at NSLS (X-25) and APS (18ID) with $0.5 \mathrm{eV}$ [40] and $1 \mathrm{eV}$ [38] resolutions, respectively as well as on XAS beamline with $1.7 \mathrm{eV}$ [19]. The comparison of our spectrum with those collected on IXS beamlines shows that the features are less pronounced even if the main ones are visible, due to the lower resolution $(2.2 \mathrm{eV})$, which dumps and merges these features. Our spectrum 


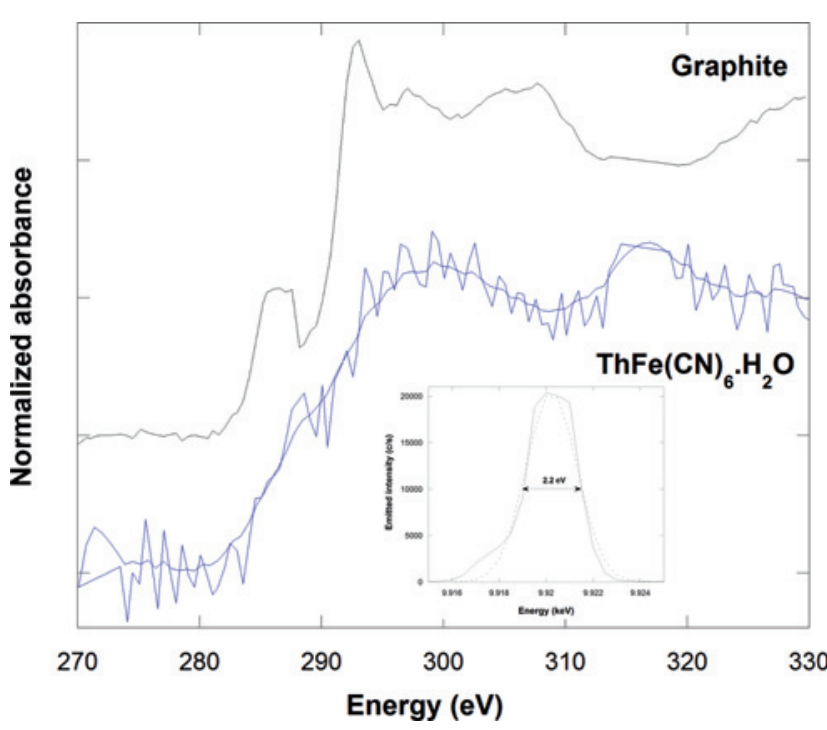

Fig. 14: The carbon $\mathrm{K}$-edge measured by X-ray-inelastic scattering for graphite and $\mathrm{ThFe}(\mathrm{CN})_{6} \cdot n \mathrm{H}_{2} \mathrm{O}$. The analyzer energy was set to $E=9.92 \mathrm{keV}$, at an incident intensity of some $4 \times 10^{11}$ photons s$^{-1}$. Inset: profile of the elastic peak.

presents the same characteristics that the one collected on CRG/BM30B-FAME beamline, the energy resolution being on the same order of magnitude in both cases (2.2 vs $1.7 \mathrm{eV})$.

Then, the CK-edge XANES spectrum in $\mathrm{FeTh}(\mathrm{CN})_{6} \cdot n \mathrm{H}_{2} \mathrm{O}$ is recorded in the same conditions as previously for graphite. After a merge of 74 spectra for a total acquisition time of $55 \mathrm{~h}$, the edge-jump is visible with $62 \mathrm{~s}^{-1}$ and $68 \mathrm{~s}^{-1}$ before and after the edge, respectively. But structures in the threshold are not resolved compared with data collected using soft X-ray (energy resolution of $0.05 \mathrm{eV}$ ) (Dumas, Den Auwer et al., PCCP submitted). However, the stability and reproducibility of the MARS beamline and spectrometer over a long period of acquisition is indeed shown by the Figure 3 giving the quasi-elastic peak of the incident beam from the sample for each NEXAFS spectrum: all these elastic spectra have the same intensity and the same shape.

\section{Conclusion and perspectives}

The beamline is open to users since 2010 for low radioactive samples (below the French exemption limit). The authorizations to study radioactive materials at ambient temperature and pressure, up to 20000 times the exemption limit, has been given by the French Safety Authority (ASN) in September 2013. Authorizations to work in different physical and chemical conditions, as well as at higher activities are foreseen in the next two years. Then the ra- dionuclide activities on MARS beamline will be among the highest currently available on the different synchrotron facilities. These very challenging experiments on high radioactive samples require innovative technical solutions for shielding the end-stations that are currently under design.

Acknowledgement: We acknowledge the help of Sandrine Schlutig and Marc Souilah from MARS beamline which are in charge of the X-ray diffraction studies on the beamline. We acknowledge also the help of M. Ribbens, P. Feret, F. Langlois, J. Bisou and L. Cosson from supporting groups of Soleil.

\section{References}

1. Rehr, J. J., Albers, R. C.: Theoretical approaches to x-ray absorption fine structure. Rev. Mod. Phys. 72, 621 (2000).

2. Konishi, H., Yokoya, A., Shiwaku, H., Motohash, H., Makita, T., Kashihara, Y., Hashimoto, S., Harami, T., Sasaki, T. A., Maeta, H., Ohno, H., Maezawa, H., Asaoka, S., Kanaya, N., Ito, K., Usami, N., Kobayashi, K.: Synchrotron radiation beamline to study radioactive materials at the Photon factory. Nucl. Instrum. Meth. A 372, 322 (1996).

3. Saitoh, Y., Nakatani, T., Matsushita, T., Agui, A., Yoshigoe, A., Teraoka, Y., Yokoya, A: First results from the actinide science beamline BL23SU at SPring-8. Source. Nucl. Instrum. Meth. A 474, 253 (2001).

4. Bargar, J. R., Brown, Jr. G.E., Evans, I., Rabedeau, T., Rowen, M., Rogers, J.: A New Hard X-ray Absorption Spectroscopy Molecular Environmental Sciences Beamline at SSRL. Speciation, Techniques and Facilities for Radioactive Materials at Synchroton Light Sources Workshop Proceedings, Grenoble, France. NEA, 380p (2000).

5. Reich, T., Bernhard, G., Geipel, G., Funke, H., Hennig, C., Rossberg, A., Matz, W., Schell, N., Nitsche, H.: The Rossendorf Beam Line ROBL - a dedicated experimental station for XAFS measurements of actinides and other radionuclides. Radiochim. Acta 88, 633 (2000).

6. Rothe, J., Butorin, S., Dardenne, K., Denecke, M. A., Kienzler, B., Löble, M., Metz, V., Seibert, A., Steppert, M., Vitova, T., Walther, C. Geckeis, H.: The INE-Beamline for actinide science at ANKA. Rev. Sci. Intrum.83, 043105 (2012).

7. Borca, C. N., Grolimund, D., Willimann, M., Meyer, B., Jefimovs, K., Vila-Comamala, J., David, C.: The microXAS beamline at the Swiss light source: Towards nano-scale imaging. J. Phys.: Conf. Ser. 186, 012003 (2009).

8. Sitaud, B., Solari, P. L., Schlutig, S., Llorens, I., Hermange, H.: Characterization of radioactive materials using the MARS beamline at the synchrotron SOLLEIL. J. Nucl. Mater. 425, 238 (2012).

9. Sitaud, B., Lequien, S., Hermange, H., Solari, P. L.: Design and status of the radioactive matter beamline at SOLEIL. Nuclear Energy Agency, Nuclear Science Publication 6288, 151 (2007). 
10. Solari, P. L., Schlutig, S., Hermange, H., Sitaud, B.: MARS, a new beamline for radioactive matter studies at SOLEIL. J. Phys.: Conf. Ser. 190, 012042 (2009).

11. Ravel, B., Newville, M.: ATHENA, ARTEMIS, HEPHAESTUS: data analysis for X-ray absorption spectroscopy using IFEFFIT. J. Synchrotron Rad. 12, 537 (2005).

12. Fuggle, J. C., Inglesfield, J. E.: Topics in Applied Physics Vol. 69, pp. 347-351, Springer-Verlag, Berlin (1992).

13. Waasmaier, D., Kirfel, A.: New analytical scattering-factor functions for free atoms and ions. Acta Cryst. A 51, 416 (1995).

14. Venault, L., Den Auwer, C., Moisy, P., Colomp, P., Scheinost, A. C., Hennig, C.: Transporting radioactive samples from the laboratory to the ESRF. ESRF News 54, 18 (2010).

15. Hennig, C., Tutschku, J., Rossberg, A., Bernhard, G., Scheinost, A. C.: Comparative EXAFS investigation of ura$\operatorname{nium}(\mathrm{VI})$ and -(IV) aquo chloro complexes in solution using a newly developed spectroelectrochemical cell. Inorg. Chem. 44, 6655 (2005).

16. Liu, X., Fiehn, B., Brendebach, B., Dardenne, K., Marquardt, C. M., Rothe, J., Denecke, M. A.: Design of a spectroelectrochemical cell for in situ XAFS studies of actinides. Actinide XAS 2008 Proceedings, NEA (2009).

17. Bessada, C., Rollet, A. L., Zanghi, D., Melin, P., Labrude, E., Brassamin, S., Pauvert, O., Thefany, C., Matsuura, H., Thiaudière, D., Sitaud, B., Solari, P. L.: A double barrier cell for high temperature EXAFS experiments in molten actinide fluoride mixtures. Nuclear Energy Agency Nucl. Sci. Document 15, 117 (2009).

18. Bordessoule, M.: Simple X-ray cameras for beam-line instrumentation. J. Phys.: Conf. Ser. 425, 192018 (2013).

19. Hazemann, J. L., Proux, O., Nassif, V., Palancher, H., Lahera, E., Da Silva, C., Braillard, A., Testemale, D., Diot, M. A., Alliot, I., Delnet, W., Manceau, A., Gélébart, F., Morand, M., Shukla, A.: High resolution spectroscopy on an X-ray absorption beamline. J. Synchrotron Rad. 16, 283 (2009).

20. LLorens, I.,Lahera, E., Delnet, W., Proux, O., Braillard, A., Hazemann, J. L., Prat, A., Testemale, D., Dermigny, Q., Gelebart, F., Morand, M., Shukla, A., Bardou, N., O. Ulrich, O., Arnaud, S., Berar, J. F., Boudet, N., B. Caillot, B., Chaurand, P., Rose, J., Doelsch, E., Martin, P., Solari, P. L.: Five-crystals spectrometer for improved fluorescence detection on an X-ray Absorption Spectroscopy beamline. Rev. Sci. Instrum. 83, 063104 (2012).

21. Collart, E., Shukla, A., Gélébart, F., Morand, M., Malgrange, C., Bardou, N., Madourib, M., Pelouard, J. L.: Spherically bent analyzers for resonant inelastic X-ray scattering with intrinsic resolution below $200 \mathrm{meV}$. J. Synchrotron Rad. 12, 473 (2005).

22. BBT Geotechnical Consultants Limited. Gunnar Field Study Summary Report. Hull, Québec, (1986).

23. Dreesen, D. R., Williams, J. M., Marple, M. L., Gladney, E. S., Perrin, D. R.: Mobility and bioavailability of uranium mill tailings contaminants. Environ. Sci. Technol. 16, 702 (1982).

24. Abdelouas, A.: Uranium mill tailings: geochemistry, mineralogy, and environmental impact. Element 2, 335 (2006).

25. Petiau, J., Calas, G., Petitmaire, D., Bianconi, A., Benfatto, M., Marcelli, A.: Delocalized vs. localized unoccupied $5 \mathrm{f}$ states and the uranium site structure in uranium oxides and glasses probed by $\mathrm{x}$-ray-absorption near-edge structure. Phys. Rev. B 34, 7350-7361 (1986).
26. Othmane, G., Allard, T., Morin, G., Sélo, M., Brest, J., LLorens, I., Chen, N., Bargar, J., Fayek, M., Calas, G.: Uranium association with iron-bearing phases in mill tailings from Gunnar, Canada. Environ. Sci. Technol. 47, 12695-12702 (2013).

27. Safi, S., Charbonnel, A. C., Creff, G., Jeanson, A., Mostapha, S., Roques, J., Simoni, E., Solari, P. L., Vidaud, C., Den Auwer, C.: Actinide Complexation with Biomimetic Phosphorylated Molecules. MRS Proceedings (2012).

28. Cote, G.: The supramolecular speciation: a key for improved understanding and modelling of chemical reactivity in complex systems. Radiochim. Acta 91, 639 (2003).

29. Wahu, S., Berthet, J.-C., Thuéry, P., Guillaumont, D., Ephritikhine, M., Guillot, R., Cote, G., Bresson, C.: Structural versatility of uranyl( $\mathrm{VI})$ nitrate complexes that involve the diamide ligand $\mathrm{Et}_{2} \mathrm{~N}(\mathrm{C}=0)\left(\mathrm{CH}_{2}\right)_{n}(\mathrm{C}=0) \mathrm{NEt}_{2}(0<n<6)$. Eur. J. Inorg. Chem 23, 3747 (2012).

30. Doriot, S., Gilbon, D., Bechade, J. L., Mathon, M. H., Legras, L., Mardon, J. P.:Zirconium in the nuclear industry. Fourteenth International Symposium, ASTM STP 1467, 175 (2004).

31. Mardon, J. P., Charquet, D., Senevat, J.: Zirconium in the nuclear industry: twelfth International Symposium, ASTM STP 1354, 505 (2000).

32. Glatzel, P., Wenga, T.-C., Kvashnina, K., Swarbrick, J., Sikora, M., Gallo, E., Smolentsev, N., Mori, A.: Reflections on hard Xray photon-in/photon-out spectroscopy for electronic structure studies. J. Electron Spectrosc. Rel. Phenom. 188, 17 (2013).

33. Degueldre, C., Martin, M., Kuri, G., Grolimund, D., Borca, C.: Plutonium-uranium mixed oxide characterization by coupling micro-X-ray diffraction and absorption investigations. J. Nucl. Mat. 416, 142 (2011).

34. Mieszczynski, C., Degueldre, C., Kuri, G., Bertsch, J., Borca, C. N.: Investigation of irradiated uranium-plutonium mixed oxide fuel by synchrotron based micro X-ray diffraction. Prog. Nucl. Energ. 57, 130 (2012).

35. Lucuta, G., Verrall, R. A., Matzke, H., Palmer, B. J.: Microstructural features of SIMFUEL-simulated high-burnup $\mathrm{UO}_{2}$-based nuclear fuel. J. Nucl. Mat. 178, 48 (1991).

36. Schükle, W., Nagasawa, H., Mourikis, S., Lanzki, P.: Dynamic structure of electrons in Li metal: Inelastic synchrotron x-ray scattering results and interpretation beyond the random-phase approximation. Phys. Rev. B 33, 6744 (1986).

37. Krisch, M. \& Sette, F.: X-ray Raman scattering from low $Z$ mate: rials. Surf. Rev. Lett. 9, 969 (2002).

38. Dumas, T., Charbonnel, M. C., Charushnikova, I. A., Conradson, S. D., Fillaux, C., Hennig, C., Moisy, P., Petit, S., Scheinost, A. C., Shuh, D. K., Tyliszczakf, T., Den Auwer, C.: Multi-edge X-ray absorption spectroscopy of thorium, neptunium and plutonium hexacyanoferrate compounds. New, J. Chem. 37, 2941 (2013).

39. Bergmann, U., Glatzel, P., Cramer, S. P.: Bulk-sensitive XAS characterization of light elements: from X-ray Raman scattering to X-ray Raman spectroscopy. Microchem. J. 71, 221 (2002).

40. Bergmann, U., Mullins, O. C., Cramer, S. P.: X-ray Raman spectroscopy of carbon in asphaltene: light element characterization with bulk sensitivity. Anal. Chem. 72, 2609 (2000). 